\title{
Photorhabdus Luminescens: Virulent Properties and Agricultural Applications
}

\author{
Elizabeth Gerdes ${ }^{1}$, Devang Upadhyay ${ }^{1,}$, , Sivanadane Mandjiny ${ }^{2}$, Rebecca Bullard-Dillard ${ }^{3}$, \\ Meredith Storms $^{4}$, Michael Menefee ${ }^{5}$, Leonard D. Holmes ${ }^{1}$ \\ ${ }^{1}$ Sartorius Stedim Biotechnology Laboratory, Biotechnology Research and Training Center, The University of North Carolina at Pembroke, \\ Pembroke, USA \\ ${ }^{2}$ Department of Chemistry and Physics, The University of North Carolina at Pembroke, Pembroke, USA \\ ${ }^{3}$ School of Graduate Studies and Research, The University of North Carolina at Pembroke, Pembroke, USA \\ ${ }^{4}$ College of Arts \& Sciences, The University of North Carolina at Pembroke, Pembroke, USA \\ ${ }^{5}$ Thomas Family Center for Entrepreneurship, The University of North Carolina at Pembroke, Pembroke, USA
}

\section{Email address:}

danny.uncp@gmail.com (D. Upadhyay)

\section{To cite this article:}

Elizabeth Gerdes, Devang Upadhyay, Sivanadane Mandjiny, Rebecca Bullard-Dillard, Meredith Storms, Michael Menefee, Leonard D. Holmes. Photorhabdus Luminescens: Virulent Properties and Agricultural Applications. American Journal of Agriculture and Forestry. Vol. 3, No. 5, 2015, pp. 171-177. doi: 10.11648/j.ajaf.20150305.12

\begin{abstract}
Photorhabdus luminescens is a gram-negative, bioluminescent bacterium from the family Enterobacteriaceae which has been found in countries across the globe. It is part of a symbiotic relationship with, and resides in the gut of the entomopathogenic nematode, Heterorhabditis bacteriophora. Photorhabdus luminescens produces many virulence factors, toxin complexes and antimicrobial compounds which allow it to kill insect hosts while simultaneously protecting itself and its symbiotic partner from other bacteria. Due to its virulent properties and the ability to infect a wide range of insect hosts, the Photorhabdus luminescens-Heterorhabditis bacteriophora relationship is a promising candidate for agricultural use as a mass produced biological control agent. The use of Photorhabdus luminescens has been deemed safe towards humans, animals, nontarget insects, plants, as well as the environment. The entomopathogenic nematode is also exempt from registration regulations in most countries. The significance of Photorhabdus luminescens is the potential for an insecticide that allows different species of insect pests to be effectively controlled by a single natural product rather than multiple chemical products. The purpose of this review is to provide readers with an overview of the safety of Photorhabdus luminescens to the community and environment, to inform readers of the virulence factors associated with the bacteria, and to outline the potential the product possesses as a mass produced biological control agent.
\end{abstract}

Keywords: Photorhabdus Luminescens, Heterorhabditis Bacteriophora, Symbiosis, Bioluminescence, Biocontrol Agent

\section{Introduction}

Photorhabdus luminescens is an insect pathogenic, gramnegative [Figure 1], bioluminescent bacterium [Figure 2] formerly known as Xenorhabdus luminescens belonging to the family Enterobacteriaceae. The carcass of the insect host becomes bioluminescent as the bacterial infection progresses [1]. The biological purpose of bioluminescence is not yet clear, however, it has been speculated to be an indicator of insect virulence [1,2]. Photorhabdus luminescens lives in the gut of the entomopathogenic nematode (EPN) Heterorhabditis bacteriophora by means of a specialized and free-living form known as the infective juvenile (IJ) [3]. This particular combination is toxic to a wide range of insects such as, Pyralidae, Sphingidae and Aleyrodidae families, thus making the P. luminescens - H. bacteriophora pairing a candidate for agricultural applications [4].

$P$. luminescens is 5 microns in length and 1 micron in width when viewed with an electron microscope [5,6]. Important properties of the $P$. luminescens bacterium are its ability to: (1) produce and secrete high-molecular-weight toxin complexes that kill the host quickly (within $24 \mathrm{~h}$ to $48 \mathrm{~h}$ ) [21]; (2) synthesize enzymes to convert the insect body into nutrients; (3) antibiotic production to inhibit competing bacteria; (4) pigmentation and (5) bioluminescence $[2,6,7,8,9]$. The bacterium lives a bi-phasic lifecycle: a nematode-symbiotic 
phase where the bacteria enter and reproduce in the nematode gut, and an insect-pathogenic phase in which the bacteria release different toxins in order to kill insect host $[6,10]$. The nematodes itself converts through 4 stages within the insect which will be discussed more thoroughly below [6].

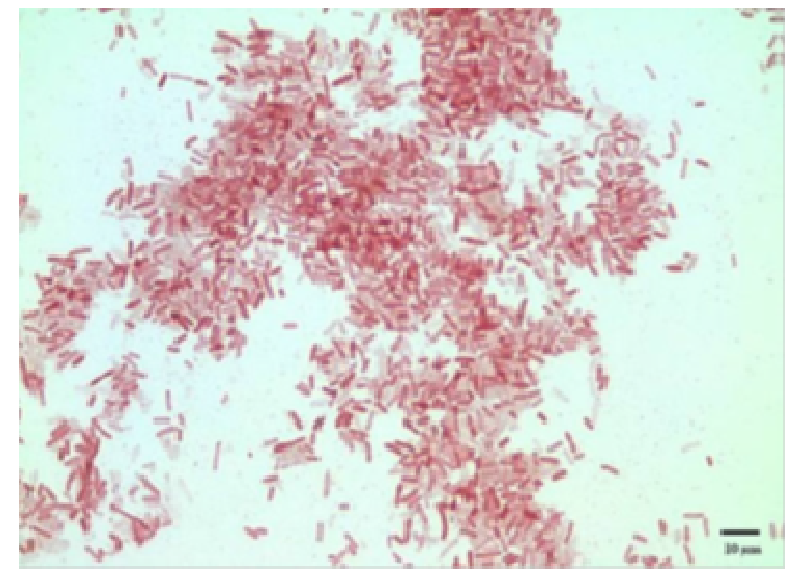

Figure 1. Gram stain of Photorhabdus luminescens. From Inman, F. L. et al. [5].

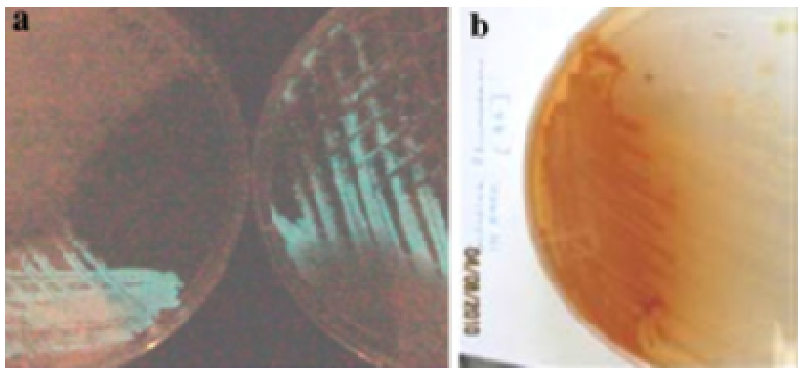

Figure 2. a: Phase I bioluminescence. $b$ : Pigmentation on rich media. From Singh, S. et al. [2].

\section{Bacterial Relationship with Heterorhabditis Bacteriophora}

The symbiotic or mutualistic relationship between Photorhabdus luminescens and Heterorhabditis bacteriophora is required for nematode viability [11]; however, the relationship is not obligate for both partners as $P$. luminescens can be cultured anoxically. In nature, $P$. luminescens releases toxins into the open bloodstream of the insect host causing the death of the insect. Insect tissue is converted by $P$. luminescens enzymes for food utilization for bacteria and the nematodes. The nematodes reproduce and move onto the next insect host. In exchange, $H$. bacteriophora allows the bacteria to enter and live in its gut until it enters the insect host by means of the insect cuticle or gut with the buccal tooth [12]. The relationship is highly specific in that Heterorhabditis bacteriophora can only pair with Photorhabdus luminescens [6].

\section{Symbiotic Life Cycle}

The life cycle of $P$. luminescens and $H$. bacteriophora is divided into four stages [Figure 3, Table 1]. Stage I, the bacteria is located in the midgut of the nematode while it searches for and enters an insect host [12]. In Stage II, the bacteria are released into the hemolymph of the insect and secrete toxins resulting in the death of the insect host [13]. It has been shown that as few as one to ten cells of $P$. luminescens can be fatal to insect hosts [12]. In Stage III, the nematodes reproduce within the insect while the bacteria produce antibiotics, exoenzymes, and crystal proteins to repel competing bacteria and convert the insect corpse into nutrients. In this stage, the nematode's ability to reproduce is dependent on the presence of the P. luminescens; therefore the relationship is both obligatory and specific. The entirety of stage II and III is complete within approximately 48 hours after initial infection of the insect host [6]. Stage IV is the final stage where the development of new nematodes occurs as well as the colonization of the nematode intestines by the bacteria [6].

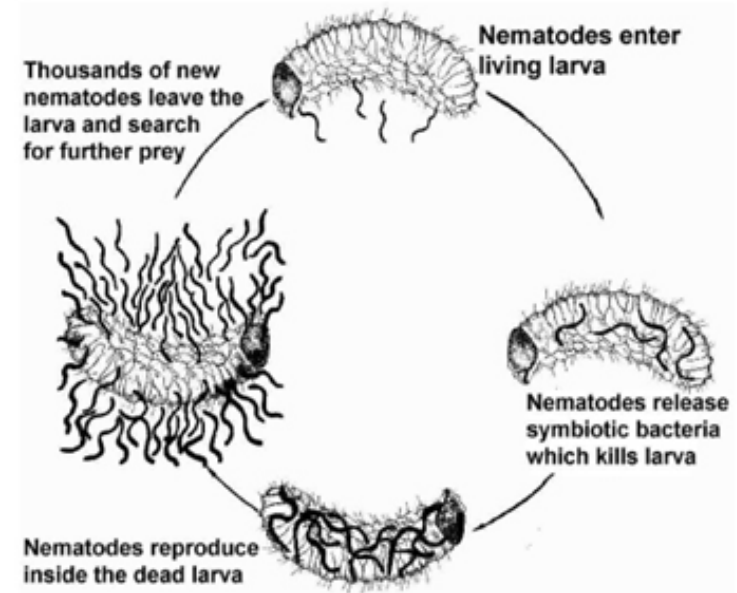

Figure 3. The life cycle of Photorhabdus luminescens. From Ehlers, R. [3].

Table 1. Stages of the symbiotic relationship between Photorhabdus luminescens and Heterorhabditis bacteriophora. From Frost, S. and Clarke, D. [12].

\begin{tabular}{|c|c|c|}
\hline Stage & Bacteria Life Cycle & Nematode Life Cycle \\
\hline I & $\begin{array}{l}\text { Bacteria retained in } \\
\text { nematode gut }\end{array}$ & $\begin{array}{l}\text { Infective juvenile in the soil } \\
\text { Search for insect host } \\
\text { Infective juvenile enters into } \\
\text { insect haemocoel }\end{array}$ \\
\hline II & $\begin{array}{l}\text { Bacteria released into } \\
\text { haemolymph } \\
\text { Production of virulence } \\
\text { factors } \\
\text { Death of insect }\end{array}$ & Recovery in the haemocoel \\
\hline III & $\begin{array}{l}\text { Bacteria in stationary phase } \\
\text { Production of antibiotics, } \\
\text { exoenzymes, crystal protein } \\
\text { Bioconversion of insect }\end{array}$ & Nematode reproduction \\
\hline IV & $\begin{array}{l}\text { Colonization of the intestine } \\
\text { of infective juveniles }\end{array}$ & $\begin{array}{l}\text { Development of new infective } \\
\text { juveniles }\end{array}$ \\
\hline
\end{tabular}

\section{Primary and Secondary Cells}

In Photorhabdus luminescens, there is a phenomenon known as phase variation in which secondary cells are 
formed [3]. Primary cells (Phase I cells) are carried by Infective Juvenile (IJ) stages of nematodes and possess numerous phenotypic traits. The secondary cells (Phase II cells) are the variant cells in which the traits of the primary cells are present at low levels or not present at all $[6,14]$. Traits lost or altered in the secondary cells include the loss of dye-binding ability, less pigmentation, fewer antibiotics produced and almost undetectable bioluminescence. Regardless of the loss of these traits in Phase II cells, it is interesting to note that the Phase II are virulent; but to a lesser extent than the Phase I cells [15]. Secondary cells also produce a protease inhibitor which accounts for the lack of protease activity compared to primary cells [6]. The presence of protease is important because it is widely believed that protease is actively involved in the breakdown of proteins in insects which would allow the bacteria and its symbiotic nematode to be able to reproduce inside the insect before moving on to the next [6].

\section{Virulence Factors}

The toxins produced by Photorhabdus luminescens are classified into four different groups: (1) the "makes caterpillars floppy" (mcf) toxins $[10,16]$; (2) the toxin complexes (Tcs) [17]; (3) the Photorhabdus insect related (Pir) proteins and (4) the Photorhabdus virulence cassettes (PVC) [25].

\subsection{The Mcf Toxin}

The mcf toxins cause cells to adopt a phenotype similar to those undergoing apoptosis [Figure 4]. Cells infected with the mcf toxins expressed changes in the morphology within 6 hours post infection. Infected cells disintegrate due to multiple cellular disruptions in the cell membrane [10]. Further studies show when injected into the insect midgut, the mcf toxins produce signs of severe infection in as little as 12 hours. The midgut of the insect is a primary organ tasked with osmoregulation and the destruction of this system would cause the floppiness associated with the mcf toxins [18].

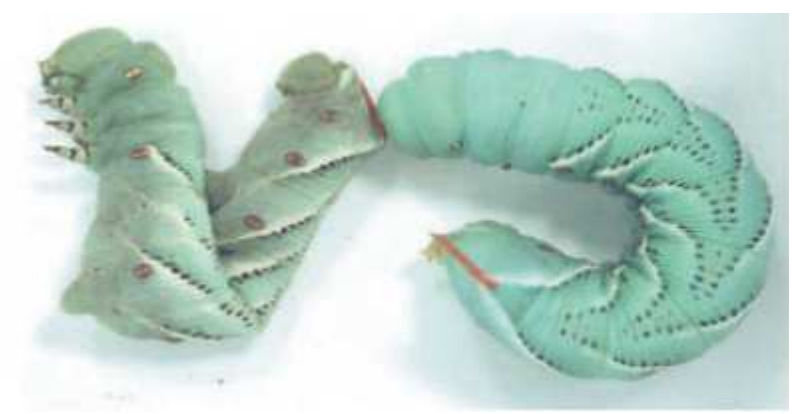

Figure 4. M. sexta 24 h after injection of mcf toxin. Caterpillar on left has lost body turgor. From Daborn, P. J. et al. [10].

\subsection{Toxin Complexes}

Photorhabdus luminescens produces toxin complexes (Tc). These are further categorized into toxin complexes $a$ through $d(t c a, t c b, t c c, t c d)$. These toxins are high molecular-weight molecules with oral insecticidal abilities. It has been suggested that the Tc toxins are fusion proteins for several different functions [19]. The toxin complex tca is active after oral delivery or injection and the median lethal dose (LD) is $875 \mathrm{ng}$ per square centimeter [20]. The ingestion of tca causes swelling and blebbing of columnar cells and the eventual loss of the cell nuclei [21]. Toxin complexes $t c a$ and $t c d$ have been shown to be responsible for most of the oral toxicity in Manduca sexta caterpillars. When the loci that form both the $t c a$ and $t c d$ complexes were deleted there was no longer any oral toxicity $[20,22,23]$. This demonstrates that the $t c a$ and $t c d$ complexes are responsible for a large majority of the oral toxicity to Manduca sexta caterpillars. It has also been shown that $t c a$ is rapidly toxic to the Colorado potato beetle and the sweet potato whitefly [24].

\subsection{Photorhabdus Insect Related (Pir) Toxins}

Photorhabdus insect related (Pir) toxins are binary proteins encoded by PirA and PirB [18,25]. There is little genetic similarity between PirA and any other known substance, however, $\operatorname{Pir} B$ is highly similar to the genetic composition of the $C r y 2 A$ insecticidal toxin suggesting a possible conserved structure and/or function for these different proteins [25]. Significantly these proteins express traits similar to the $\delta$-endotoxins of Bacillus thuringiensis $(\mathrm{Bt})$ which is currently used as a crop pesticide. The similarity allows for the possibility of using Photorhabdus luminescens and its symbiotic nematode, Heterorhabditis bacteriophora as an alternative to $\mathrm{Bt}$ for crop pesticides [25].

\subsection{Photorhabdus Virulence Cassettes (PVC) and Lipases}

Lipase activity has been shown to be present mainly in Photorhabdus luminescens primary cells, but secondary cells produce low levels of lipase activity as well. The lip-1 lipase gene in P. luminescens has been cloned from secondary cells and shown to be secreted in an inactivated form displaying entomotoxic ability towards the greater wax moth, Galleria mellonella [6]. Photorhabdus virulence cassettes (PVCs) are phage-like loci responsible for an "anti-feeding" effect in insects. P. luminescens strain TT01 contains many copies of the prophage-like loci that are each tasked with encoding different proteins. PVCs of Photorhabdus luminescens have no proven antibacterial abilities. However, the injection of PVCs destroys the hemocytes of the insect which causes cytoskeleton damage. It has been suggested that PVCs may be important in the formation of virulent properties against multiple types of insects [18].

\section{Antimicrobial Compounds}

In order to allow for the reproduction of the bacteria and its symbiotic nematode, $P$. luminescens produces antimicrobial compounds which prevent other bacteria, unrelated as well as related, from colonizing the insect host carcass while nematode reproduction is taking place $[8,26]$. 
One of the main antimicrobial compounds found to be produced and secreted by Photorhabdus luminescens are carbapenems, members of the $\beta$-lactam class of antibiotics. Carbapenems possess a broad potency to both gram-negative and gram-positive bacteria [27]. It has been suggested these carbapenems are produced by a cluster of 8 different genes referred to as cpmA to $c p m H$. It is clear that there are more antimicrobial compounds being produced by $P$. luminescens due to the observation of inhibition zones in tests involving cpm mutations. Also, inhibition zone studies have shown that these carbapenem-like molecules are not effective against gram-positive bacteria [Figure 5] [27]. A known antibiotic, 3,5-dihydroxy-4-isopropylstilbene [Figure 6], has been isolated from a strain of $P$. luminescens and it was shown that this compound was produced rapidly during the first day of culture and then declined until it was hardly detectable in the sample [28]. This test proved that 3,5-dihydroxy-4isopropylstilbene possesses a strong antifungal potential for agricultural and medical applications. It is also fairly easy to manufacture, making it potential supplement for current pesticides and insecticides employed in agricultural [26].

\begin{tabular}{|c|cc|c|cc|}
\hline Indicator strain & TT01 & PL2101 & Indicator strain & TT01 & PL2101 \\
\hline Escherichia coli & $\bigcirc$ & 0 & $\begin{array}{c}\text { Enterobacter } \\
\text { cloacae } \\
\text { T39180297 }\end{array}$ & $\bigcirc$ & \\
\hline $\begin{array}{c}\text { Enterobacter } \\
\text { cloacae } \\
39177636\end{array}$ & 0 & 0 & $\begin{array}{c}\text { Pseudomonas } \\
\text { aeruginosa }\end{array}$ & 0 & \\
\hline $\begin{array}{c}\text { Klebsiella } \\
\text { pneumoniae }\end{array}$ & 0 & 0 & $\begin{array}{c}\text { Xanthomonas } \\
\text { maltophilia }\end{array}$ & $\bigcirc$ \\
\hline
\end{tabular}

Figure 5. Activity of P. luminescens shown by antibiosis.

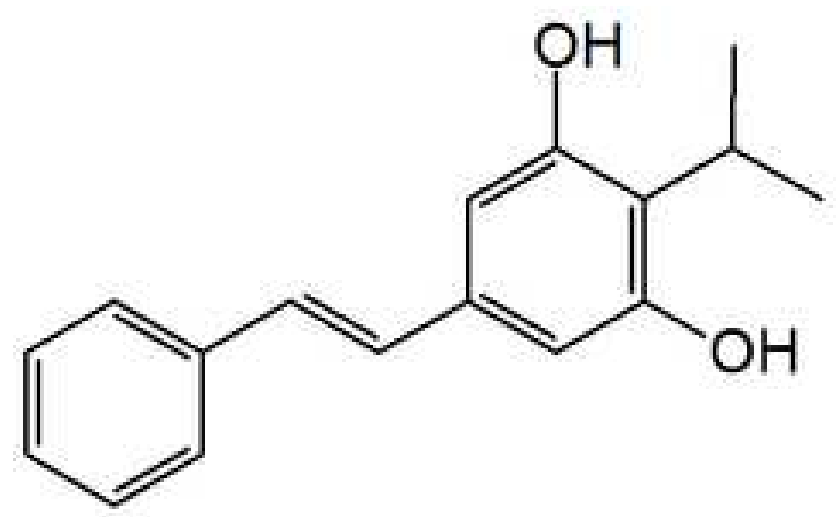

Figure 6. Structure of 3,5-dihydroxy-4-isopropylstilbene. From Li, J. et al. [28].

After 3 days, LB plates were spotted with Photorhabdus luminescens strain TT01 and Photorhabdus luminescens strain PL2101 were inoculated with various indicator strain cultures in soft agar. Growth inhibition around a spot shows production of antibiotics that the indicator strain is sensitive to the antibiotics produced. This figure shows that the inhibition zones of the TT01 strain were larger than those of the PL2101 strain under similar conditions. The zones seen in the PL2101 strain are likely due to other antibiotics produced by the Photorhabdus luminescens bacteria. From Derzelle, S. et al. [27].

\section{Agricultural Applications}

The fear that insect pests may develop resistance to the widely used pesticide, Bacillus thuringiensis (Bt), has encouraged scientists to explore alternative pesticides and insecticides. This exploration has brought them to the Photorhabdus luminescens bacteria and their symbiotic nematode, Heterorhabditis bacteriophora as a potential alternative for insects that have developed a resistance to $\mathrm{Bt}$ This is a highly probable solution to the problem of insect resistance because, other than the few documented cases of opportunistic cultivation of an open wound, the use of this bacteria-nematode relationship as a pesticide has shown no adverse consequences to humans, wildlife, or plants and therefore, is a highly attractive option [29,30]. Another approach that some scientists have experimented with is plant mutations that would allow plants to be able to defend themselves against pests. But, it was determined that it does not provide the same levels of protection that the use of direct methods, such as Bt [31].

There are many positive qualities of the Photorhabdus luminescens-Heterorhabditis bacteriophora relationship as an insecticide which include: 1) its wide range of insect hosts; 2) safety to humans, non-target insects, animals, plants, and the environment and 3) its exemption to registration in many countries [3].

\subsection{The Wide Range of Insect Hosts}

The Photorhabdus luminescens-Heterorhabditis bacteriophora relationship has virulence towards a large number of different insects when tested in the laboratory. Due to the wide variety of susceptible insects, this bacterianematode relationship has developed the ability for versatile penetration routes that can be taken depending on the insect's defenses which could be a high defecation rate, low carbon dioxide output to minimize attention, cocoons, the quarantine of infected insects, and other grooming or evasive behaviors [32].

\subsection{Safety to Humans, Non-Target Insects, Animals, Plants, and Environment}

The $H$. bacteriophora nematodes infected with $P$. luminescens can be used as an insecticide to prevent insect populations of certain pests from growing too large. $P$. luminescens - H. bacteriophora provide a safe alternative for Bt pesticides. The symbionts show no negative side effects towards the environment, which means that use will not harm the soil or the water supply. Traditional chemical inputs can seep into soil, thus contaminating ground water. The symbiont will not harm wildlife because this combination resides in the soil where most wildlife will not come into contact with them [3].

\subsection{Exemption from Registration in Most Countries}

Nematodes with their bacteria symbionts have been found in soils across the world. The $P$. luminescens - $H$. 
bacteriophora symbiotic pair has been recovered from soils in countries with continental and Mediterranean climates and has been isolated from soil in Turkey [32]. Most European countries, Australia, and the United States do not require the registration of indigenous nematodes while other countries require similar procedures to that of chemical pesticides $[3,32]$.

\section{Application Challenges}

On the other hand, the negative aspects include (1) the inability to tolerate environmental changes and (2) the potential problems related to mass production and transportation.

\subsection{Tolerance to Environmental Changes}

Having a higher tolerance for heat would allow this bacteria-nematode combination to be stored for longer periods of time and in a wider variety of locations than is currently possible [33]. The ability for lower temperature tolerance would allow the nematodes and their symbiotic bacteria to be used in colder climates. It has been shown that modified strains of the Heterorhabditis bacteriophora can successfully survive at temperatures as high as 39 degrees Celsius and as low as 6 degrees Celsius [33], However, Photorhabdus luminescens cannot be stored at such varied temperatures. Photorhabdus luminescens can be stored in the gut of their symbiont nematodes in refrigerated tanks with an oxygen supply for long periods of time (between 3 and 6 months) or they can be used immediately. This storage method requires refrigeration to protect quality and that is where scientists and businesses run into the problem of mass storage. Scientists have begun researching ways to alter the bacteria in order to allow for a higher heat tolerance as well as a lower cold tolerance for easier transportation and storage [33].

\subsection{Challenges with Mass Production and Transportation}

The most cost-effective means of mass production of this Photorhabdus luminescens-Heterorhabditis bacteriophora combination is in liquid media using bioreactors because it offers the ability to produce a high yield and the media is relatively inexpensive when compared to solid media components. However, the initial costs of liquid fermentation are exponentially higher due to the advanced equipment required for the process. Many developing countries use invivo methods because it is reliable and it produces high quality nematodes with Phase I bacteria. The in-vivo method is problematic for mass production, because it is costly and labor intensive [32]. Larger companies most often use liquid fermentation because it is the most profitable since the profit increases as the production costs decrease [34]. The down side is that this method is highly susceptible to contamination and the bacteria must be kept in their Phase I during production and transportation in order to remain virulent [3].

\section{Conclusion}

Discoveries to date have not yet produced a comprehensive list of the agricultural uses and benefits of the Photorhabdus luminescens and Heterorhabditis bacteriophora relationship but, the relationship does have a promising future in the agricultural industry that has yet to be fully defined. The use of this bacteria-nematode combination as a biological control agent offers a product that is safe, effective, cost effective, and easy to apply to crops. This will save time and money without allowing potentially harmful chemicals to be introduced into the environment and become potential hazards to animals and humans. There are many promising abilities held by this bacteria-nematode combination which make it a highly viable alternative: (1) The wide range of insect hosts; (2) being exempt from regulation in many countries and (3) the unique virulence factors associated with the Photorhabdus luminescens bacterium. There are still a few unresolved negative issues such as the bacteria's intolerance to extreme temperatures, the issues involved in storage, and the high cost of mass production. Finally, more field-testing must continue to promote wider acceptance of this bio-control product. Once these issues are addressed and resolved, the viability of the bacteria-nematode relationship as biological control agents will be widely recognized.

\section{Acknowledgments}

Financial support was provided, in part, by the: Farm Bureau of Robeson County, North Carolina; University of North Carolina at Pembroke (UNCP) Office of the Provost and Academic Affairs; UNCP Department of Chemistry and Physics; North Carolina Biotechnology Center (NCBC) and UNCP Thomas Family Center.

\section{References}

[1] Daborn, P., Waterfield, N., Blight, M. A. and Ffrench-Constant, R. H. (2001) Measuring Virulence Factor Expression by the Pathogenic Bacterium Photorhabdus luminescens in Culture and during Insect Infection. Journal of Bacteriology, 183(20): 5834-5839.

[2] Singh, S., Moreau, E., Inman, F. and Holmes, L. D. (2011) Characterization of Photorhabdus luminescens Growth for the Rearing of the Bacterial Nematode Heterorhabditis bacteriophora. Indian Journal of Microbial, 52(3): 325-331.

[3] Ehlers, R. (2001) Mass production of entomopathogenic nematodes from plant protection. Applied Microbiology and Biotechnology, 56: 623-633.

[4] Kooliyottil. R, Upadhyay, D., Inman, III F., Mandjiny, S. and Holmes, L.D. (2013) A Comparative Analysis of Entomoparasitic Nematodes Heterorhabditis bacteriophora and Steinernema carpocapsae. Open Journal of Animal Science, 3(4): 326-333. 
[5] Inman, F. L. III, Singh, S. and Holmes, L. D. (2012) Mass Production of the Beneficial Nematode Heterorhabditis bacteriophora and Its Bacterial Symbiont Photorhabdus luminescens. Indian Journal of Microbial, 52(3): 316-324.

[6] Frost, S. and Clarke, D. (2002) Bacteria-Nematode Symbiosis. In Gaugler R. (Ed.) Entomopathogenic Nematology (pp 5777).

[7] Marokhazi, J., Waterfield, N., LeGoff, G., Feil, E., Stabler, R., Hinds, J., Fodor, A. and Ffrench-Constant, R. H. (2003) Using a DNA Microarray To Investigate the Distribution of Insect Virulence Factors in Strains of Photorhabdus Bacteria. Journal of Microbiology, 185(15): 4648-4656.

[8] Ffrench-Constant, R. H., Waterfield, N., Burland, V., Perna, N. T., Daborn, P. J., Bowen, D. and Blattner, F. R. (2000) A Genomic Sample Sequence of the Entomopathogenic Bacterium Photorhabdus luminescens W14: Potential Implications for Virulence. Applied and Environmental Microbiology, 66(8): 3310-3329.

[9] Schmidt, T. M., Kopecky, K. and Nealsoni, K. H. (1989) Bioluminescence of the Insect Pathogen Xenorhabdus luminescens. Applied and Environmental Microbiology, 55(10): 2607-2612.

[10] Daborn, P. J., Waterfield, N., Silva, C. P., Au, C. P. Y., Sharma, S. and Ffrench-Constant, R.H. (2002) A single Photorhabdus gene, makes caterpillars floppy (mcf), allows Escherichia coli to persist within and kill insects. Proceedings of the National Academy of Sciences, 99 (16): 10742-10747.

[11] Patterson, W., Upadhyay, D., Mandjiny, S., Bullard-Dillard, R., Storms, M., Menefee, M. and Holmes, L. D. (2015) Attractant Role of Bacterial Bioluminescence of Photorhabdus luminescens on a Galleria mellonella Model. American Journal of Life Sciences, 3(4): 290-294.

[12] Ciche, T. and Ensign, J. C. (2002) For the Insect Pathogen Photorhabdus luminescens, Which End of a Nematode Is Out? Applied and Environmental Microbiology, 69(4): 1890-1897.

[13] Guo, L., Fatig III, R. O., Orr, G. L., Schafer, B. W., Strickland, J. A., Sukhapinda, K., Woodsworth, A. T. and Petell, J. K. (1999) Photorhabdus luminescens W-14 Insecticidal Activity Consists of at Least Two Similar but Distinct Proteins. The Journal of Biological Chemistry, 274(14): 9836-9842.

[14] Bowen, D. J. and Ensign, J. C. (1998) Purification and Characterization of a High-Molecular-Weight Insecticidal Protein Complex Produced by the Entomopathogenic Bacterium Photorhabdus luminescens. Applied and Environmental Microbiology, 64(8): 3029-3035.

[15] Dowds, B. C.A. and Peters, A. (2002) Virulence Mechanisms. In Gaugler R. (Ed.) Entomopathogenic Nematology (pp 7998).

[16] Derzelle, S., Turlin, E., Duchaud, E., Pages, S., Kunst, F., Givaudan, A. and Danchin, A. (2003) The PhoP-PhoQ TwoComponent Regulatory System of Photorhabdus luminescens Is Essential for Virulence in Insects. Journal of Microbiology, 186(5): 1270-1279.

[17] Brillard, J., Duchaud, E., Boemare, N., Kunst, F. and Givaudan, A. (2002) The PhIA Hemolysin from the Entomopathogenic Bacterium Photorhabdus luminescens Belongs to the Two-Partner Secretion Family of Hemolysins. Journal of Bacteriology, 184(14): 3871-3878.
[18] Ffrench-Constant, R. H., Dowling, A. and Waterfield, N. R. (2007) Insecticidal toxins from Photorhabdus bacteria and their potential use in agriculture. Toxicon, 49: 436-451.

[19] Waterfield, N., Bowen, D. J., Fetherston, J. D., Perry, R. D. and Ffrench-Constant, R. H. (2001) The tc genes of Photorhabdus: a growing family. Trends in Microbiology, 9(4): 185-191.

[20] Bowen, D., Rocheleau, T. A., Blackburn, M., Andreev, O., Golubeva, E., Bhartia, R. and Ffrench-Constant, R. H. (1998) Insecticidal Toxins from the Bacterium Photorhabdus luminescens. Science Magazine, 280: Pages 2129-2132.

[21] Blackburn, M., Golubeva, E., Bowen, D. and FfrenchConstant, R. (1998) A Novel Insecticidal Toxin from Photorhabdus luminescens, Toxin Complex a (Tca), and Its Histopathological Effects on the Midgut of Manduca sexta. Applied and Environmental Microbiology, 64(8): 3036-3041.

[22] Ffrench-Constant, R. H. and Bowen, D. J. (2000) Novel insecticidal toxins from nematode-symbiotic bacteria. Cellular and Molecular Life Sciences, 57: 828-833.

[23] Pinheiro, V. and Ellar, D. J. (2007) Expression and insecticidal activity of Yersinia pseudotuberculosis and Photorhabdus luminescens toxin complex proteins. Cellular Microbiology, 9: 2372-2380.

[24] Blackburn, M. B., Domek, J. M., Gelman, D. B. and Hu, J. S. (2005) The broadly insecticidal Photorhabdus luminescens toxin complex a (Tca): Activity against the Colorado potato beetle, Leptinotarsa decemlineata, and sweet potato whitefly, Bemisia tabaci. Journal of Insect Science, 5(32): 1-11.

[25] Rodou, A., Ankrah, D. O. and Stathopoulos, C. (2010) Toxins and Secretion Systems of Photorhabdus luminescens. Toxins, 2: $1250-1264$.

[26] Bondi, M., Messi, P., Sabia, C., Baccarani C. M. and Manicardi, G. (1998) Antimicrobial Properties and Morphological Characteristics Of Two Photorhabdus luminescens strains. Microbiologica, 22: 117-127.

[27] Derzelle, S., Duchaud, E., Kunst, F., Danchin, A. and Bertin, P. (2002) Identification, Characterization, and Regulation of a Cluster of Genes Involved in Carbapenem Biosynthesis in Photorhabdus luminescens. Applied and Environmental Microbiology, 68(8): 3780-3789.

[28] Li, J., Chen, G., Wu, H. and Webster, J. M. (1995) Identification of Two Pigments and a Hydroxystilbene Antibiotic from Photorhabdus luminescens. Applied and Environmental Microbiology, 61(12): 4329-4333.

[29] Peel, M. M., Alfredson, D. A., Gerrard, J. G., Davis, J. M., Robson, J. M., McDougall, R. J., Scullie, B. L. and Akhurst, R. J. (1999) Isolation, Identification, and Molecular Characterization of Strains of Photorhabdus luminescens from Infected Humans in Australia. Journal of Clinical Microbiology, 37(11): 3647-3653.

[30] Morgan, J.A.W., Kuntzelmann, V., Tavernor, S., Ousley, M.A. and Winstanley, C. (1997) Survival of Xenorhabdus nematophilus and Photorhabdus luminescens in water and soil. Journal of Applied Microbiology, 83: 665-670.

[31] Ferry, N., Edwards, M. G., Gatehouse, J. A. and Gatehouse, A. M.R. (2004) Plant-insect interactions: molecular approaches to insect resistance. Current Opinion in Biotechnology, 15: $155-161$. 
[32] Hazir, S., Kaya, H. K., Stock, S. P. and Keckun, N. (2003) Entomopathogenic Nematodes (Steinernematidae and Heterorhabditidae) for Biological Control of Soil Pests. Turkish Journal of Biology, 27:181-202.

[33] Ehlers, R., Oestergaard, J., Hollmer, S., Wingen, M. and Strauch, O. (2005) Genetic selection for heat tolerance and low temperature activity of the entomopathogenic nematodebacterium complex Heterorhabditis bacteriophoraPhotorhabdus luminescens. BioControl, 50: 699-716.

[34] Upadhyay, D., Kooliyottil, R., Mandjiny, S., Inman, III F. and Holmes, L. (2013) Mass production of the beneficial nematode Steinernema carpocapsae utilizing a fed-batch culturing process. EScience Journal of Plant Pathology, 02(01): $52-58$.
[35] Mahajan-Miklos, S., Rahme, L. G. and Ausubel, F. M. (2000) Elucidating the molecular mechanisms of bacterial virulence using non-mammalian hosts. Molecular Microbiology, 37: 981-988.

[36] Eleftherianos, I., Marokhazi, J., Millichap, P.J., Hodgkinson, A.J., Sriboonlert, A., Ffrench-Constant, R.H. and Reynolds, S.E. (2006) Prior infection of Manduca sexta with nonpathogenic Escherichia coli elicits immunity to pathogenic Photorhabdus luminescens: Roles of immune-related proteins shown by RNA interference. Insect Biochemistry and Molecular Biology, 36: 517-525. 